\title{
Exposure to benzene, occupational stress, and reduced birth weight
}

Dafang Chen, Sung-Il Cho, Changzhong Chen, Xiaobin Wang, Andrew I Damokosh, Louise Ryan, Thomas J Smith, David C Christiani, Xiping Xu
Department of Environmental Health, Harvard School of Public Health, 665 Huntington Avenue, FXB-101 Boston, MA 02115-6096, USA D Chen

S-I Cho

C Chen

$\mathrm{X}$ Wang

A I Damokosh

T J Smith

D C Christiani

$\mathrm{XXu}$

Center for

Ecogenetics, Beijing

Medical University,

Beijing, China

D Chen

Department of Pediatrics, Boston University School of Medicine, and Boston Medical Center, Boston, USA

X Wang

Department of Biostatistics, Harvard School of Public Health and

Dana-Farber Cancer Institute, Harvard

Medical School,

Boston, USA

L Ryan

Massachusetts General Hospital, Harvard Medical School, Boston, USA

D C Christiani

Channing Laboratory, Brigham and Women's Hospital, Harvard Medical School, USA $\mathrm{XXu}$

Correspondence to: Dr Xiping Xu xu@hsph.harvard.edu

Accepted 25 May 2000

\begin{abstract}
Objectives-The association between birth weight and exposure to benzene, work stress, and other occupational and environmental hazards was investigated. Methods-In a large petrochemical industry, 792 pregnant workers were enrolled and followed up through delivery between May 1996 and December 1998. Exposure to benzene and other solvents was assessed by an industrial hygienist based on each woman's job title and workplace information. Other occupational and environmental exposures and personal information, including perceived work stress, exposure to noise, physical exertion at work, and passive smoking, were obtained by an interview questionnaire. Univariate and multivariate regression models were used to examine the individual and combined associations of occupational and environmental exposures with birth weight, with adjustment for major confounders including gestational age.
\end{abstract}

Results-In the univariate model, birth weight was negatively associated with exposure to benzene ( $-58 \mathrm{~g}(95 \%$ confidence interval $(95 \% \mathrm{CI}),-115$ to -2$))$ and with work stress $(-84 \mathrm{~g}(95 \% \mathrm{CI},-158$ to $-10)$ ). In the multivariate model, there was a significant interaction between exposure to benzene and work stress relative to reduced birth weight, after adjustment for other environmental and occupational exposures and personal variables. Adjusted mean birth weight was $3445 \mathrm{~g}(95 \%$ CI 3401 to 3489$)$ among those with neither exposure, $3430 \mathrm{~g}$ for those with exposure to benzene only, $3426 \mathrm{~g}$ for those with work stress only, and $3262 \mathrm{~g}$ (95\% CI 3156 to 3369$)$ for those with both exposures. In other words, there was $183 \mathrm{~g}$ (95\% CI 65 to 301$)$ reduction in birth weight among those with both exposure to benzene and work stress compared with those with neither exposure. Other work or environmental factors could not explain these findings.

Conclusions-Low level exposure to benzene and work stress interact to reduce birth weight in this population.

(Occup Environ Med 2000;57:661-667)

Keywords: birth weight; benzene; work stress

With an increasing number of women entering the work force world wide, women are exposed to various reproductive toxins. A growing body of evidence shows an association between environmental and occupational exposures and adverse reproductive outcomes. Studies have examined exposures to cigarette smoke, ${ }^{12}$ caffeine, ${ }^{3}$ pesticides, ${ }^{45}$ air pollution, ${ }^{67}$ organic solvents, ${ }^{8-13}$ and occupational stress. ${ }^{14}$

Exposure to solvents is ubiquitous in the general population. Ashley et $a l^{15}$ measured the organic solvents in the blood of about 600 subjects without occupational exposure in the third national health and nutrition examination survey (NHANES III). Detectable concentrations of benzene, xylene, styrene, toluene, tricholoroethane, and other volatile organic chemicals were found in most of the blood samples. Organic solvents are also commonly used in the workplace. The National Institute for Occupational Safety and Health ${ }^{16}$ estimated that 9.8 million workers in the United States were occupationally exposed to solvents. Organic solvents identified as potential reproductive toxins include benzene, ${ }^{8917}$ toluene, ${ }^{10-12}$ and related compounds. ${ }^{13} \mathrm{Al}-$ though the level of exposure in most modern industrial working environments is far below the limit recommended by OSHA, studies have begun to suggest that even low level occupational exposure to organic solvents is linked to a broad range of adverse reproductive outcomes. ${ }^{17-19}$ Furthermore, it is increasingly recognised that a person is usually exposed to many environmental and occupational hazards. Most previous studies examined a specific exposure without simultaneously considering other exposures. There is little information on how multiple environmental and occupational exposures interact and affect reproductive outcomes.

The purpose of this study was to investigate the association between reduced birth weight and prenatal exposure to low concentrations of benzene and a range of other common environmental and occupational hazards and to examine potential interactions among those exposures in a large cohort of female workers in a modern petrochemical plant in Beijing, China.

Methods

STUDY SITE

This study was conducted in Beijing Yanshan Petrochemical Corporation (BYPC), in a suburban area of Beijing, China. The BYPC, in operation since 1986, has over 47000 employees and consists of 17 major production plants and institutes for petroleum and chemical processing. About $40 \%$ of its employees are women. The major occupational exposures are 
to benzene, toluene, styrene, and xylene. As BYPC is a modern industry, the level of exposure is very low. For example, the time weighted average (TWA) for benzene during the shift for exposed workers ranged from $0.017 \mathrm{ppm}$ (rubber plant) to $0.191 \mathrm{ppm}$ (chemical plant No 1$)^{20}$ with an overall mean of $0.112 \mathrm{ppm}$ and a median of $0.033 \mathrm{ppm}$, a concentration far below the limit of $1 \mathrm{ppm}$ as an 8 hour TWA recommended by OSHA. ${ }^{21}$ Concentrations of other solvents, such as styrene, toluene, and xylene, were all below $1 \mathrm{ppm}$, far below the OSHA standard. ${ }^{20}$ About $80 \%$ of local residents are employed at BYPC. In general, pregnant employees stop working at about 28 weeks of gestation.

The BYPC Staff Hospital is the only regional hospital that serves the local community and the employees of BYPC. It is a large hospital affiliated with Beijing Medical University. The obstetrics department of the hospital has 50 delivery beds. All BYPC female workers are entitled to receive free medical care including routine health examination, family planning counselling, prenatal care, delivery service, and neonatal care. On confirmation of pregnancy, each prospective mother is scheduled for antenatal visits and is given a maternity notebook to record examination findings at each visit and the dates of subsequent visits.

\section{STUDY POPULATION AND PROCEDURE}

Eligible women were current BYPC employees who had a single live birth at the BYPC staff hospital between May 1996 and December 1998. Those who had multiple gestation, births with major congenital defects, or a medically diagnosed gynaecological or endocrine disorder were excluded from the study. Among eligible subjects, participation rate was over $92 \%$. The study protocol was approved by the institutional review boards of Harvard School of Public Health and Beijing Medical University. A total of 1237 eligible women were enrolled on confirmation of a clinical pregnancy. After informed consent was obtained, a previously validated questionnaire ${ }^{17}$ was administered by trained interviewers to obtain information on demographic characteristics, cigarette smoking, alcohol consumption, diet, physical activity, occupational exposure, and medical and reproductive history. Clinical data including prepregnancy weight and height, the first day of the last menstrual period, findings of each prenatal visit, and birth outcomes (including the infant's sex, gestational age, and birth weight) were recorded by a trained nurse.

ASSESSMENT OF EXPOSURE TO BENZENE AND OTHER SOLVENTS

We based maternal exposure to benzene on a specialised industrial hygiene method developed in three steps. Firstly, a walk through field study was conducted by an industrial hygienist to obtain detailed information on the production processes in each of the plants. Information was obtained on different sections of the plant known as workshops, including raw materials, end products, chemical reaction processes, and the job titles involved in the production. Location maps and flow charts of the chemical reaction processes were also prepared for each workshop. A qualitative description of typical job tasks was provided for major production workshops. Each of the plants had a different number of workshops. In total, 218 workshops were identified, and a list of 104 job titles was constructed.

Secondly, on a subset of 132 workers, two different methods of assessment of exposure were compared. For each woman in this subgroup, personal air sampling was conducted on a randomly chosen workday. Quantitative chemical measurements were performed for benzene, toluene, styrene, and xylene. If a detectable concentration of any chemical was measured, the woman was classified as exposed to the specific solvent. The second method was based on an industrial hygienist's assessment of each woman's plant, workshop, and job title information. A standardised algorithm was developed to classify each worker into either exposed or unexposed to each of the four solvents, respectively. For example, in the workshops where benzene was present as a raw material or end product, all the workers were classified as exposed to benzene. If a woman did not work primarily in such a workshop, but had a job title that required tasks in the exposed areas, she was also rated as exposed to benzene. Thus, operators who worked in such facilities as refinery, rubber plant, oil blending workshop, benzene tank farm, or phenol production workshop, were rated as exposed, and workers in the electricity control room, packing workshop, workers' union, administration office, information centre, or the library, were considered to be unexposed. The industrial hygienist's assessment was compared with the classification based on detection of chemicals from air samples. The sensitivity and specificity of the hygienist's qualitative assessment was reasonably high for benzene ( 0.70 and 0.62 , respectively). However, sensitivity was below 0.4 for toluene, styrene, and xylene.

Thirdly, a trained interviewer obtained information on plant, workshop, and job title from all women participants. Based on the standardised algorithm developed in the validation stage, an industrial hygienist classified each woman's exposure into three categories without knowledge of birth outcomes. Women who were exposed to benzene with or without other exposures were classified as exposed to benzene. Women who were not exposed to benzene but potentially to other solvents were grouped as exposed to other solvents. Finally, women who were not exposed to any solvents were classified as unexposed. Further details of the exposure assessment method and validation results are described elsewhere..$^{20}$

\section{OTHER OCCUPATIONAL EXPOSURES AND}

PERSONAL INFORMATION

To identify each woman's exposures to reproductive hazards other than solvents, a trained interviewer used a detailed checklist constructed from toxicology literature. Exposures to 26 different chemical and physical hazards 
were reported by 108 participants ( 86 exposed to benzene, 22 unexposed). The frequency of exposure to each specific hazard was low, ranging from 1 to 11 . Therefore, a combined variable was formed as exposure to other reproductive hazards. Information on other occupational exposures such as noise (yes/no), vibration (yes/no), dust/fumes (yes/no), rotating shift work (yes/no), main work posture (sitting, standing, squatting, mobile, and other), frequency of lifting work (never, sometimes, always), physical exertion (light, moderate, heavy), and perceived work stress (no or low, moderate, high) were also obtained from the questionnaire interview. Perceived work stress was assessed by a person's response to the question "How stressed do you feel at your workplace? (1=no or low, $2=$ moderate, $3=$ high)." Data were also collected on personal variables including maternal age, education, date of marriage, weight and height before pregnancy, general health, medical history, use of contraceptives, reproductive history, active and passive smoking at home and at work, alcohol consumption, use of herbal medicines, and indoor air pollution. Passive smoking at work and at home was based on a person's response to the question "Do your colleagues in your office or work room smoke while they are on duty?" and "Are there any people who live with you who smoke?", respectively. To the extent that these factors relate to exposure to benzene and birth weight, adjustment was made for these factors in the data analysis. It is noted that many workers reported a rotating shiftwork, but in fact, most of them were able to sleep during their shift. As there is considerable misclassification of this variable, we decided not to include it in the data analysis.

ASSESSMENT OF BIRTH OUTCOMES

In this study, birth weight was measured in the delivery room by a trained nurse and was accurate to $10 \mathrm{~g}$. The first day of the last menstrual period recorded on the first prenatal visit was used to estimate the gestational age. It was accurate in this population for several reasons. In China, married couples who plan to have a child need to apply for birth permission at the local family planning administration. In essence, all births are planned, and couples will try to conceive once they have obtained birth permission. Due to the one child policy, families are highly concerned about healthy pregnancy and healthy babies. All the women in our study population sought prenatal care and had a pregnancy test soon after missing a menstrual period. Furthermore, the gestational age was calculated in exact days instead of rounded completed weeks as in most epidemiological studies.

STATISTICAL ANALYSIS

Among 1237 eligible women enrolled, the sample for the analysis consisted of 825 women with well defined exposure: those who were exposed to benzene $(n=366)$ and those who were not exposed to any organic solvents $(n=459)$. Women who were exposed to other solvents $(n=412)$ were excluded due to the concern of exposure misclassification. Among 825 women included in the analyses, a small number of women who smoked $(n=2)$ or drank $(n=22)$ during the pregnancy were excluded. Another nine women were excluded because of missing information on smoking or alcohol use during pregnancy. The final sample size for the analysis includes 792 women (354 benzene exposed, and 438 non-exposed).

Birth weight is the primary outcome of interest. It represents an end point of fetal growth. Reduced birth weight can result from preterm delivery, retardation of intrauterine growth, or both. This study specifically focused on adverse effects of environmental and occupational hazards on intrauterine growth; therefore, all the regression models adjusted for gestational age. To adequately adjust for gestational age, we examined the functional relation between gestational age and birth weight, and found that inclusion of both linear and quadratic terms fitted the model best.

We used linear regression models to examine the individual and combined associations between birth weight and major occupational and environmental exposures including benzene, noise, vibration, dust, perceived work stress, exposure to reproductive toxins other than solvents, lifting, physical exertion, main work posture, and passive smoking. All the exposure variables were treated as binary or dummy variables. Perceived work stress and physical exertion were dichotomised (low $v$ moderate or high) because the highest category contained fewer than 20 subjects. We also investigated potential interactions of multiple occupational exposures on birth weight. Inclusion of exposure to benzene, stress, and the interaction of the two significantly contributed to the basic model as did gestational age $(\mathrm{p}=0.03$, partial $F$ test). None of the other interactions were detectable. None of the covariates examined changed the effect estimate for the interaction term between benzene and stress by more than $5 \%$. The addition of the variable "working mainly in a sitting posture" changed the main effect of exposure to benzene by more than $15 \%$; therefore this variable was included in the final model.

All the multivariate models adjusted for known or potentially important confound$\mathrm{ers}^{23}{ }^{24}$ including maternal age (categorised into 20-25, 26-29, and 30-40), height and body mass index (BMI) tertiles before pregnancy, education (college $v$ lower), parity ( $\geqslant 1 v$ none), infant sex, exposure to noise, physical exertion, and exposure to other hazard". The final model showed a good fit with the residuals showing no significant departure from normal distribution ( $\mathrm{p}>0.10$, Shapiro-Wilk test).

\section{Results}

Maternal and infant characteristics by maternal exposure to benzene are presented in table 1. This is an overall low risk population, with most women at their optimal reproductive ages, most being the ideal weight for height, non-smokers, and non-alcohol drinkers. The overall mean (SD) birth weight for this sample was 3427 (441) g. The gestational age had a 
Table 1 Characteristics of the study population, Beijing Yanshan Petrochemical Corporation, China

\begin{tabular}{|c|c|c|}
\hline & $\begin{array}{l}\text { No exposure } \\
(n=438) \text { mean }(S D)\end{array}$ & $\begin{array}{l}\text { Exposure to benzene } \\
(n=354) \text { mean }(S D)\end{array}$ \\
\hline Age (y) & $27.0(2.4)$ & $26.7(1.9)$ \\
\hline Duration of employment (y) & $5.7(3.0)$ & $6.3(2.7)$ \\
\hline Weight before pregnancy (kg) & $57.8(9.3)$ & $58.3(9.7)$ \\
\hline Height before pregnancy $(\mathrm{cm})$ & $161.5(5.0)$ & $161.0(4.7)$ \\
\hline BMI before pregnancy $\left(\mathrm{kg} / \mathrm{m}^{2}\right)$ & $22.2(3.5)$ & $22.5(3.6)$ \\
\hline Birth weight $(\mathrm{g})$ & $3464 \quad(429)$ & 3382 (451) \\
\hline \multirow[t]{2}{*}{ Gestational age (weeks) } & $40.0(1.3)$ & $39.8(1.5)$ \\
\hline & $n \quad(\%)$ & $n \quad(\%)$ \\
\hline \multicolumn{3}{|l|}{ Age (y): } \\
\hline $20-25$ & $94 \quad(21.5)$ & $70 \quad(19.8)$ \\
\hline $26-29$ & $276 \quad(63.0)$ & $250 \quad(70.6)$ \\
\hline $30-40$ & $68 \quad(15.5)$ & $34 \quad(9.6)$ \\
\hline \multicolumn{3}{|l|}{ Education: } \\
\hline Middle school or lower & $45 \quad(10.3)$ & $33 \quad(9.3)$ \\
\hline High school & $217 \quad(49.5)$ & $247 \quad(69.8)$ \\
\hline College or above & $176 \quad(40.2)$ & $74 \quad(20.9)$ \\
\hline Passive smoking at home or work & $239 \quad(55.6)$ & $218 \quad(61.8)$ \\
\hline Parity (one or more) & $18 \quad(4.1)$ & $14 \quad(4.0)$ \\
\hline Female baby & $215 \quad(49.1)$ & $171 \quad(48.7)$ \\
\hline Work stress & $85 \quad(19.4)$ & $57 \quad(16.1)$ \\
\hline Noise & $56 \quad(13.0)$ & $151 \quad(42.8)$ \\
\hline Physical exertion & $105 \quad(24.0)$ & $89 \quad(25.1)$ \\
\hline Other hazards & $22 \quad(5.0)$ & $86 \quad(24.3)$ \\
\hline Work mainly in a sitting posture & $250 \quad(57.1)$ & $245 \quad(69.2)$ \\
\hline
\end{tabular}

Table 2 Crude association of birth weight with environmental and occupational exposures and maternal and infant characteristics

\begin{tabular}{|c|c|c|c|c|}
\hline Variable & $n$ & $\begin{array}{l}\text { Estimated } \\
\text { change in birth } \\
\text { weight }\end{array}$ & $p$ Value & $(95 \% C I)$ \\
\hline \multicolumn{5}{|l|}{ Maternal characteristics: } \\
\hline \multicolumn{5}{|l|}{ Age (y): } \\
\hline $20-25$ & 164 & Referent & & \multirow{3}{*}{$\begin{array}{l}(-50 \text { to } 91) \\
\text { (68 to } 266)\end{array}$} \\
\hline $26-29$ & 526 & 21 & 0.559 & \\
\hline $30-40$ & 102 & 167 & 0.001 & \\
\hline \multicolumn{5}{|c|}{ Height tertile before pregnancy $(\mathrm{cm})$ : } \\
\hline 1 st $(147-159)$ & 244 & Referent & & \multirow{3}{*}{$\begin{array}{l}(-43 \text { to } 92) \\
\text { (40 to } 184)\end{array}$} \\
\hline 2nd (160-163) & 314 & 24 & 0.478 & \\
\hline $3 \mathrm{rd}(164-180)$ & 234 & 112 & 0.003 & \\
\hline \multicolumn{5}{|c|}{ BMI tertile before pregnancy $\left(\mathrm{kg} / \mathrm{m}^{2}\right)$ : } \\
\hline $1(14.17-20.31)$ & 264 & Referent & & \multirow{5}{*}{$\begin{array}{l}(-5 \text { to } 133) \\
(31 \text { to } 168) \\
(28 \text { to } 149) \\
(-109 \text { to } 4)\end{array}$} \\
\hline $2(20.32-23.42)$ & 260 & 64 & 0.068 & \\
\hline $3(23.43-37.46)$ & 268 & 100 & 0.004 & \\
\hline College education or above & 250 & 89 & 0.004 & \\
\hline Passive smoking & 457 & -53 & 0.066 & \\
\hline \multicolumn{5}{|l|}{ Infant characteristics: } \\
\hline Parity (one or more) & 32 & 83 & 0.257 & \multirow{2}{*}{$\begin{array}{l}(-60 \text { to } 25) \\
(-153 \text { to }-40)\end{array}$} \\
\hline Female baby & 386 & -97 & 0.001 & \\
\hline \multicolumn{5}{|l|}{ Occupational exposures: } \\
\hline Exposure to benzene & 354 & -58 & 0.044 & \multirow{6}{*}{$\begin{array}{l}(-115 \text { to }-2) \\
(-158 \text { to }-10) \\
(-100 \text { to } 29) \\
(-98 \text { to } 33) \\
(-112 \text { to } 52) \\
(-41 \text { to } 76)\end{array}$} \\
\hline Perceived work stress & 142 & -84 & 0.026 & \\
\hline Noise at work & 207 & -36 & 0.275 & \\
\hline Physical exertion & 194 & -32 & 0.337 & \\
\hline Other hazards & 108 & -30 & 0.471 & \\
\hline Work mainly in a sitting posture & 495 & 18 & 0.552 & \\
\hline
\end{tabular}

*All the estimates were derived from a linear regression model with adjustment for a linear and a square terms of gestational age.

Table 3 Adjusted association of birth weight with selected environmental and occupational exposures

\begin{tabular}{lccl}
\hline Variable & $\begin{array}{l}\text { Estimated }{ }^{*} \text { change } \\
\text { in birth weight }\end{array}$ & p Value & (95\% CI) \\
\hline Benzene exposure & -15 & 0.655 & $(-82$ to 52) \\
Work stress & -19 & 0.702 & $(-115$ to 78$)$ \\
Benzene-stress interaction & -149 & 0.048 & $(-296$ to -1$)$ \\
Noise exposure & 14 & 0.697 & $(-55$ to 82$)$ \\
Physical exertion & -10 & 0.767 & $(-58$ to 78$)$ \\
Other hazards & -16 & 0.711 & $(-101$ to 69$)$ \\
Work mainly in a sitting posture & 12 & 0.701 & $(-50$ to 73$)$ \\
Passive smoking at home or work & -36 & 0.200 & $(-92$ to 19$)$
\end{tabular}

^All the estimates were derived from a multiple linear regression model including maternal age, education, parity, height and body mass index before pregnancy, infant sex, linear and quadratic terms of gestational age, and the other listed variables.

near normal distribution, with a mean (SD) of 39.9 weeks (1.4) and a range from 33 to 44 weeks. The women in the exposed and non-exposed groups were similar for age distri-

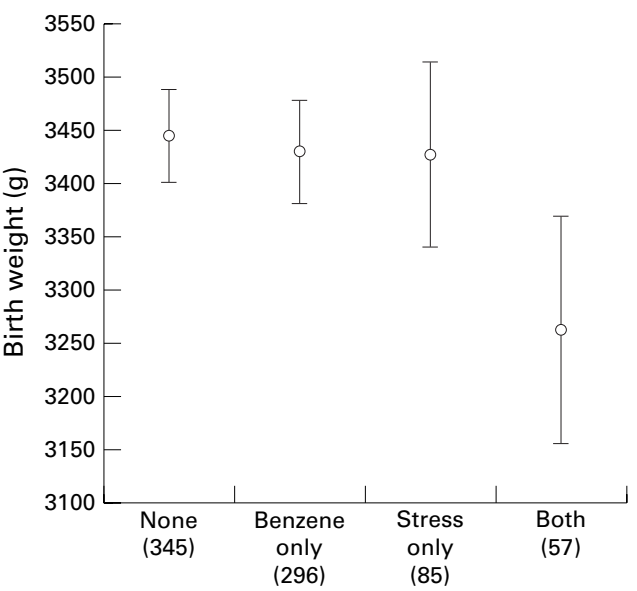

Birth weight by exposure to benzene and stress. Adjusted birth weight $(g)$ for four subgroups defined by maternal exposure to benzene and work stress: group 1 has no exposure to benzene and no work stress (none); group 2 (stress only); group 3 (benzene only); and group 4 (both). The numbers in parentheses indicate the number of women in each category (see table 3 for the list of variables adjusted for).

bution, years of employment, stress, maternal weight and height before pregnancy, parity, and infant sex. However, the women in the exposed group were less likely to have a college education and more likely to be exposed to noise and passive smoke. The mean birth weight was $82 \mathrm{~g}$ lighter and the mean gestational age 0.2 weeks shorter for the group exposed to benzene than for the unexposed group.

Table 2 presents the association between birth weight and each personal, environmental, and occupational factor, with adjustment for gestational age. Consistent with the available literature, taller stature, larger BMI, higher parity, and higher education were each associated with increased birth weight, whereas female sex and passive smoking were associated with decreased birth weight. Although the exposure to benzene was low in this population, it was significantly associated with reduced birth weight $(-58 ; 95 \%$ confidence interval $(95 \% \mathrm{CI})-115$ to -2$)$. Perceived work stress was also significantly associated with reduced birth weight $(-84 ; 95 \% \mathrm{CI}-158$ to $-10)$. Exposure to noise, other hazards, physical exertion, and work posture were not significantly associated with birth weight.

These associations were further evaluated by multivariate analysis. The multivariate regression model included exposure to benzene, work stress, and the variables listed in table 2 . The interaction term was also included in the model (table 3 ) because there was a significant interaction between exposure to benzene and perceived work stress. The figure illustrates the interactive relation: the adjusted mean birth weight was $3445 \mathrm{~g}$ (95\% CI 3401 to 3489) among those without exposure to benzene and work stress, $3430 \mathrm{~g}$ (95\% CI 3382 to 3477) for those with only exposure to benzene, $3426 \mathrm{~g}$ (95\% CI 3340 to 3513) for those with only work stress, and $3262 \mathrm{~g}$ (95\% CI 3156 to 3369) for those with exposure to both benzene and work stress. The group with both exposures showed a 183 g reduction $(95 \%$ 
CI 65 to 301) in birth weight compared with those with neither exposure.

\section{Discussion}

In both developed and developing countries, low birth weight $(<2500 \mathrm{~g})$ is the single most important predictor of neonatal mortality and is a major determinant of post-neonatal mortality and morbidity. ${ }^{25}$ There is growing evidence that many environmental and occupational factors are associated with reduced birth weight. ${ }^{2324}$ In this study, we investigated the association between birth weight and a range of potential environmental and occupational hazards, in particular, exposure to benzene and work stress. After adjusting for gestational age and other major maternal and infant covariates, we found that low exposure to benzene was significantly associated with reduced birth weight. More remarkably, there was a significant interaction between exposure to benzene and work stress, resulting in a much greater reduction in birth weight among those with both exposure to benzene and work stress, than among those without either.

This study has several characteristics. It is one of the few studies to examine low exposure to benzene relative to birth weight; it is based on many female workers from a modern petrochemical plant, where epidemiological and clinical data were collected with a validated questionnaire and consistent methods were used by trained research staff and where occupational exposure was measured by objective exposure assessment; and it is overall a low risk and relatively homogeneous population in terms of sociodemographic factors, which offers an opportunity to examine exposure to low concentrations of organic solvents and other occupational hazards relative to birth weight without many influential confounders. Assessment of exposure to low concentrations of organic solvents poses a challenge in epidemiological studies. In the current study, an extensive effort was made to develop an objective and cost efficient method with reasonable sensitivity and specificity.

This study examined a large range of occupational and environmental exposures and potential interactions. Especially, we examined whether any other personal, occupational, or environmental variables could explain the reduced birth weight among women with exposure to both benzene and stress. None of the factors substantially changed the effect of the benzene-stress interaction term by inclusion in or exclusion from the model. As production processes and work environments have been well characterised in our study population, it is not very likely that there was an unrecognised environmental or occupational exposure that could significantly alter our study findings.

Our findings are consistent with previous epidemiological studies. Benzene and other organic solvents have been identified as potential reproductive toxins..$^{8-13} 17$ Wilkins and Steele ${ }^{26}$ reported that the risk of preterm delivery was increased among female veterinarians exposed to solvents. Witkowski and Johnson ${ }^{27}$ noted an increased risk of low birth weight among women who consumed drinking water polluted by benzene or other solvents. In a recent study of 125 women exposed to solvents and 125 matched controls, ${ }^{28}$ an increased frequency of birth defects was found in the exposed group. As a secondary result, birth weight was also significantly lower among the exposed group. There have been strong suggestions that maternal stress is associated with preterm birth and low birth weight. A prospective study of 90 women showed that episodic and chronic stress factors were significantly associated with reduced birth weight and shortened gestational age at birth. ${ }^{29}$ In a larger prospective study among 2593 women, stress measured by a 28 item Likert scale was significantly associated with preterm birth and low birth weight. ${ }^{30}$ The results of our study are consistent with the previous studies for the effect of exposure to benzene and maternal stress separately. However, in our study the effect was most distinct among women who had both factors.

The biological mechanisms by which benzene and work stress affect birth weight remain to be determined. Benzene is known to produce several toxic metabolites that affect rapidly growing cells such as bone marrow, cause oxidative damage in the cells, and suppress cell growth. ${ }^{31} 32$ In animal studies benzene and other aromatic organic solvents have consistently been shown to be fetotoxic, resulting in delayed fetal development and reduced birth weight. ${ }^{33-35}$ The mechanism by which maternal stress affects birth outcome was thought to be through stress dependent hormones or immunological pathways. ${ }^{36}$ Stress results in the release of various adrenal and hypothalamic stress hormones, which enhance placental, decidual, and amniochorionic expression of corticotropin releasing hormone. ${ }^{37}$ McLean et $a l^{8}$ found that, compared with women delivering at term, women delivering preterm had significantly increased plasma corticotropin releasing hormone between 16 and 30 weeks of gestation, whereas women delivering post-term had significantly decreased plasma concentrations of corticotropin releasing hormone. Our study suggests that there may be biological synergism between the causal pathways of benzene and stress relative to birth weight.

Our study findings have the following implications. As exposure to organic solvents is prevalent in the general population, even a small amount of shift in the mean birth weight distribution curve towards the left among those exposed may translate into a significantly increased number of low birth weight infants, thus contributing to a significant aetiological fraction of low birth weight. This study documents that exposure to benzene even at a concentration five times below the limit recommended by OSHA is significantly associated with reduced birth weight, which raises the occupational health issues for women of reproductive age even in a modern petrochemical industry. The finding of significant benzene and work stress interaction suggests the 
importance of assessing potential multiple exposure interactions for future assessment of reproductive risk among women workers.

When the results of this study are interpreted, several methodological limitations should be taken into account. We studied a low risk population with low exposure to benzene as the major occupational exposure, so the generalisability of our findings to women in other populations is unknown. A doseresponse relation between exposure to benzene and birth weight could not be examined due to a lack of data on individual cumulative exposures. The main occupational exposure in this study population was benzene. Our analysis excluded those women who were exposed to other organic solvents but not to benzene. However, among women exposed to benzene, we could not completely exclude the possibility that they might be exposed to very low concentrations of other organic solvents as well. Nevertheless, the observed association should be largely attributed to benzene. Our assessment of perceived stress was based on a simple question to classify the level of stress into three categories: no or low, moderate, and high. This is a subjective measure. However, the data were obtained without the knowledge of the birth weight of the infant and the misclassification is expected to be non-differential, likely resulting in a conservative effect estimate. Previous studies by other investigators ${ }^{39}{ }^{40}$ have linked self perceived stress with adverse pregnancy outcomes. The measure of stress used in the current study has been validated in our earlier studies. In a retrospective study of 3343 women workers in BYPC, ${ }^{19}$ we found a significant exposure-response relation between the three levels of perceived stress and the frequency of abnormal duration of the menstrual cycle, a result consistent with the studies that used more detailed assessment of perceived stress. ${ }^{39}$ In another study of 1035 women working in textile mills in Anhui, China, we found a similar pattern of significant exposure-response relations between the levels of perceived stress and the frequency of dysmenorrhoea. ${ }^{14}$ Finally, this is the first report of an interaction between benzene and work stress affecting birth weight. Further studies are clearly needed to corroborate our findings.

In summary, this study has shown that exposure to benzene at a low concentration, well below $1 \mathrm{ppm}$, was associated with reduced birth weight. More importantly, this study has shown a significant interaction between exposure to benzene and work stress in relation to reduced birth weight. Future assessment of reproductive risk among women workers should not only examine the dose-response relation of a particular exposure, but also take into consideration coexistent exposures as well as interactions among these exposures.

This study is supported in part by grants 1 R01 HD32505-01 from the National Institute of Child Health and Human Development; 1R01 ES08337-01 from the National Institute of Environmental Health Science; 1R01 OH03027 from the National Institute of Occupational Safety and Health; and G73B1382 from the Environmental Protection Agency; and by grant 20-FY98-0701 from the March of Dimes Birth Defects grant $20-$ FY $98-0701$ from the March of Dimes Birth Defects
Foundation. DC is supported in part by Fogarty International
Center Training Grant TW00828. We are grateful to Dr Douglas Dockery for his insightful review and constructive comments.

1 Kline J, Stein ZA, Susser M, et al. Smoking: a risk factor for spontaneous abortion. N Engl f Med 1977; 297:793-6.

2 Windham GC, Swan SH, Fenster L. Parental cigarette smoking and the risk of spontaneous abortion. Am f Epidemiol 1992;135:1394-403.

3 Dlugosz L, Belanger K, Hellenbrand K, et al. Maternal caffeine consumption and spontaneous abortion: a prospective cohort study. Epidemiology 1996;7:250-5.

4 Nurminen T, Rantala K, Kurppa K, et al. Agricultural work during pregnancy and selected structural malformations in Finland. Epidemiology 1995;6:23-30.

5 Schwartz DA, Newsum K, Heifetz RM. Parental occupation and birth outcomes in an agricultural community. Scand $\mathcal{F}$ Work Environ Health 1986;12:51-4.

$6 \mathrm{Xu}$ X, Ding H, Wang X. Acute effects of total suspended particles and sulfur dioxides on preterm delivery: a community-based cohort study. Arch Environ Health 1995; 0:407-15.

7 Wang X, Ding H, Ryan L, et al. Association between air pollution and low birth weight: a community-based study. Environ Health Perspect 1997;105:514-20.

8 Savitz DA, Whelan EA, Kleckner RC. Effect of parents' occupational exposures on risk of stillbirth, preterm delivery, and small-for-gestational infants. Am F Epidemiol 1989; 129:1210-18.

9 Brown-Woodman PDC, Webster WS, Picker K, et al. In vitro assessment of individual and interactive effects of aromatic hydrocarbons on embryonic development of the rat. Reprod Toxicol 1994;8:121-35.

10 Hersh JH, Podruch PE, Rogers G, et al. Toluene embryopathy. F Pediatr 1985;106:9227.

11 Lindbohm M-L. Effects of parental exposure to solvents on pregnancy outcome. F Occup Environ Med 1995;37:90814.

$12 \mathrm{Ng}$ TP, Foo SC, Yoong T. Menstrual function in workers exposed to tolune. Br f Ind Med 1992;49:799-803.

13 Sallmen M, Lindbohm M-L, Kyyronen P, et al. Reduced fertility among women exposed to organic solvents. Am $\mathcal{F}$ Ind Med 1995;27:699-713.

14 Christiani DC, Niu T, Xu X. Occupational stress and dysmenorrhea in women working in cotton textile mills. Int f Occup Environ Health 1995;1:9-15.

15 Ashley DL, Bonin MA, Cardinali FL, et al. Blood concentrations of volatile organic compounds in a nonoccupationally exposed US population and in groups with suspected exposure. Clin Chem 1994;40:1401-4.

16 National Institute for Occupational Safety and Health. National Institute for Occupational Safety and Hea
Organic solvent neurotoxicity. Cincinnati: NIOSH, 1987.

$17 \mathrm{Xu} \mathrm{X}$, Cho S-I, Sammel M, et al. Association of petrochemical exposure with spontaneous abortion. Occup Environ

18 Lemasters GK, Olsen DM, Yiin JH, et al. Male reproductive effects of solvent and fuel exposure during aircraft maintenance. Reprod Toxicol 1999;13:155-66.

19 Thurston SW, Ryan L, Christiani DC, et al. Petrochemical exposure, ergonomic factors and menstrual disturbances. Am F Ind Med 2000; (in press).

20 Withdrawn.

21 Occupational Safety and Health Administration. Timeweighted average limit. Occupational safety and health standards. Benzene. Washington, DC: US OSHA, Code of Federal Regulations, 1987

$22 \mathrm{Hu}$ YA, Smith TJ, Xu X, et al. Comparison of selfassessment of solvent exposure with measurement and assessment of solvent exposure with measurement and
professional assessment. Am f Ind Med 2000; (in press).

23 Kramer MS. Determinants of low birth weight: methodological assessment and meta-analysis. Bull World Health Organ 1987;65:663-737.

24 Silbergeld E, Tonat K. Investing in prevention: opportunities to prevent disease and reduce health care costs by identifying environmental and occupational causes of noncancer disease. Toxicol Ind Health 1994;10:675-827.

25 McCormick MC. The contribution of low birth weight to infant mortality and childhood morbidity. $N$ Engl $\mathcal{F} M e d$ 1985;312:82-90

26 Wilkins JRr, Steele LL. Occupational factors and reproductive outcomes among a cohort of female veterinarians. $\mathcal{F}$ Am Vet Med Assoc 1998;213:61-7.

27 Witkowski KM, Johnson NE. Organic-solvent water polluWitkowski KM, Johnson NE. Organic-solvent water pollu-
tion and low birth weight in Michigan. Soc Biol 1992;39: $45-54$.

28 Khattak S, K-Moghtader G, McMartin K, et al. Pregnancy outcome following gestational exposure to organic solvents. A prospective controlled study. $\mathscr{F} A M A$ 1998;281:1106-9.

29 Wadhwa PD, Sandman CA, Porto M, et al. The association between prenatal stress and infant birth weight and gestational age at birth: a prospective investigation. $A m \mathcal{F}$ Obstet Gynecol 1993;169:858-65.

30 Copper RL, Goldenberg RL, Das A, et al. The preterm prediction study: maternal stress is associated with spontaneous preterm birth at less than 35 weeks' gestation. $A m$ f Obstet Gynecol 1996;175:1286-92.

31 Laskin JD, Rao NR, Punjabi CJ, et al. Distinct actions of benzene and its metabolites on nitric oxide production by bone marrow leukocytes. F Leukoc Biol 1995;57:422-6.

32 Rao NR, Snyder R. Oxidative modifications produced in HL-60 cells on exposure to benzene metabolites. $\mathcal{f} A p p l$ Toxicol 1995;15:403-9. 
33 Ungvary G, Tatrai E. On the embryotoxic effects of benzene and its aklyl derivaties in mice, rats and rabbits. Arch Toxicol and its aklyl derivaties

34 Coate WB, Hoberman AM, Durloo RS. Inhalation teratology tudy of benzene in rats. Advances in Modern Environmental Toxicology 1984;6:187-98.

35 Seidenberg JM, Anderson DG, Becker RA. Validation of an in vivo developmental toxicity screen in the mouse. Teratog Carcinog Mutagen 1986;6:361-74.

36 Paarlberg KM, Vingerhoets AJ, Passchier J, et al. Psychosocial factors and pregnancy outcome: a review with emphasis on methodological issues. F Psychosom Res 1995;39:56395.
37 Sandman CA, Wadhwa PD, Chicz-DeMet A, et al. Maternal stress, HPA activity, and fetal/infant outcome. Ann $N Y$ stress, HPA activity, and feta
Acad Sci 1997;814:266-75.

38 McLean M, Bisits A, Davies J, et al. A placental clock controlling the length of human pregnancy. Nat Med 1995;1:460-3

39 Harlow SD, Matanoski GM. The association between weight, physical activity, and stress and variation in the length of menstrual cycle. Am F Epidemiol 1991;133:38-49.

40 Lobel M, Dunkel-Schetter C, Scrimshaw SC. Prenatal maternal stress and prematurity: a prospective study of socioeconomically disadvantaged women. Health Psychol 1992;11:32-40

\section{Correspondence and editorials}

Occupational and Environmental Medicine welcomes correspondence relating to any of the material appearing in the journal. Results from preliminary or small scale studies may also be published in the correspondence column if this seems appropriate. Letters should be not more than 500 words in length and contain a minimum of references. Tables and figures should be kept to an absolute minimum. Letters are accepted on the understanding that they be subject to editorial revision and shortening.

The journal also publishes editorials which are normally specially commissioned. The Editor welcomes suggestions regarding suitable topics; those wishing to submit an editorial, however, should do so only after discussion with the Editor. 